\title{
Communication Interventions and Fear of Brown Bears: Considerations of Content and Format
}

\author{
Maria Johansson ${ }^{1 *}$, Lars Hallgren ${ }^{2}$, Anders Flykt ${ }^{3}$, Ole-Gunnar Støen ${ }^{4}$, Linda Thelin ${ }^{5}$ and \\ Jens Frank ${ }^{6}$ \\ ${ }^{1}$ Environmental Psychology, Department of Architecture and the Built Environment, Lund University, Lund, Sweden, \\ ${ }^{2}$ Department of Urban and Rural Development, Swedish University of Agricultural Sciences, Uppsala, Sweden, ${ }^{3}$ Department \\ of Psychology and Social Work, Mid Sweden University, Östersund, Sweden, ${ }^{4}$ Norwegian Institute for Nature Research \\ (NINA), Trondheim, Norway, ${ }^{5}$ Rovdjurscentret De 5 Stora, Järvsö, Sweden, ${ }^{6}$ Grimsö Wildlife Research Station, Department \\ of Ecology, Swedish University of Agricultural Sciences, Riddarhyttan, Sweden
}

OPEN ACCESS

Edited by:

Tasos Hovardas,

University of Cyprus, Cyprus

Reviewed by:

Carina Lundmark,

Luleå University of

Technology, Sweden

Juliette Young,

Natural Environment Research Council

(NERC), United Kingdom

${ }^{*}$ Correspondence:

Maria Johansson

maria.johansson@arkitektur.Ith.se

Specialty section:

This article was submitted to

Conservation,

a section of the journal

Frontiers in Ecology and Evolution

Received: 30 August 2019 Accepted: 22 November 2019 Published: 10 December 2019

Citation:

Johansson M, Hallgren L, Flykt A,

Støen O-G, Thelin L and Frank J (2019) Communication Interventions and Fear of Brown Bears:

Considerations of Content and

Format. Front. Ecol. Evol. 7:475.

doi: 10.3389/fevo.2019.00475
Communication interventions are commonly proposed as a way to address people's fear and negative attitudes to build tolerance in shared landscapes between humans and large carnivores. Therefore, managing authorities sometimes respond to people's fear of brown bears (Ursus arctos) by organizing an information meeting. This study increases the understanding of the information meeting to address fear of encountering brown bears. Using a mixed-method approach the study analyzes the explicit meta-communication, i.e., verbal interactions to coordinate communication between presenter and participants, the effects of the meeting on fear and fear-related variables over time, and how these effects compare with the effects of a visit to a permanent brown bear exhibition, and the effects of a guided walk with exposure to brown bears and their habitat as two alternative communication interventions. Participation in information meetings contributed to reduce self-reported fear and the effect lasted over at least 6 months. The information meetings were, as assessed immediately after participation, less efficient than participation in a guided walk, but more efficient than a visit to a permanent brown bear exhibition in reducing fear. The content and format of the meeting was in line with the expectations of an information meeting, e.g., the presenter dominated the initiative in the explicit meta-communication, but still allowing for misconceptions and misunderstandings to be addressed and solved. In the development of communication strategies to address fear of large carnivores, managing authorities should pay attention to details in information content and format as well as to trade-offs between the number of people reached by the intervention and the strength of the effects on fear and fear-related variables among participants.

Keywords: self-reported fear, brown bear, intervention, information meeting, exposure, exhibition, metacommunication

\section{INTRODUCTION}

Due to conservation efforts, many large carnivore populations are increasing and recolonizing areas where they have been absent for a long time (Chapron et al., 2014; Ripple et al., 2014). This expansion has increased the risk of encounters between humans and large carnivores (LCs) (Penteriani et al., 2016; Støen et al., 2018). Even if the risk of getting harmed is extremely low 
(see Støen et al., 2018), humans harmed by large animals tend to draw much attention from the media and may go viral worldwide (Bombieri et al., 2018). Research on human dimensions of wildlife suggests that increased likelihood of encountering LCs in the wild may be appreciated by some, but feared by others (Manfredo, 2008; Johansson and Karlsson, 2011; Jacobs, 2012), this is reflected in the case of the growing brown bear (Ursus arctos) population in Sweden. In the Swedish national management plan for brown bears 2014-2019 (Anon, 2016), it is stated that the proportion of Swedes who report that they are often or always afraid of meeting a brown bear when being outdoors should be decreased by $10 \%$ over the management period. The main path to obtain this goal has been provision of information about brown bears with the objective to facilitate increased knowledge and address fear of these animals among the public. "If people just knew more about brown bears then they would not be afraid" is an argument often stated among wildlife managers. This approach is in line with the scientific literature that commonly proposes information as a way to address people's fear and negative attitudes to build tolerance in shared landscapes between humans and LCs (Slagle et al., 2013; Johansson et al., 2016a; Arbieu et al., 2019). Communication between wildlife managers and stakeholders, and the public, is critical in conservation efforts (Decker et al., 2012; Redpath et al., 2013), but the effect of information when bears impact on human interest is disputed. Evaluations of interventions are inconsistent with regard to the content and format of information provided, species concerned, and outcome variables assessed (e.g., Dunn et al., 2008; Gore et al., 2008; Baruch-Mordo et al., 2011).

In what situations information about brown bears is useful and how the information should be presented in order to meet communication goals related to fear calls for social scientists and ecologists to work together (Clayton et al., 2013). This has been realized in Sweden for some years, and different interventions have been developed based on research in wildlife ecology and psychology as well as current management practice (Johansson et al., 2016c, 2017, 2019). It is, however, not until now fully comparable data are available for comparisons across interventions. This study puts the information meeting in the center as this intervention is most commonly used in the Swedish context, but also wildlife exhibitions are available throughout the country, and exposure to the feared animal or its habitat is a third intervention recently developed (Johansson et al., 2019). The study contributes to previous research by comparing these three interventions with regard to the strength of their effect on self-reported fear of brown bears. The interventions differ in the level of effort and cost, as well as in communication practice. Still the interventions have in common that they are located to specific settings rather than provided via media.

The presence of LCs is a contested issue and there are strong opinions on the management of these animal species (SjölanderLindqvist, 2009). In communication research it is well-known that differences in expectations on communication content and format may result in both surprise and frustration. In the latter case it may even result in communication breakdown (Schegloff, 1992; Watson, 2009). In the information meeting representatives from authorities provide information to people who may have different views on management and who may express low trust in managing authorities in a setting where opportunities for dialogue may be limited. In most cases differences in expectations about communication are negotiated and managed through the explicit meta-communication. Therefore, it is essential to the information meeting intervention to also gain knowledge about how meta-communication operates and unfolds. The study contributes by increasing the understanding of the explicit meta-communication (here operationalized as the interaction performed through explicit verbal expressions to coordinate the communication between presenter and participants) of the information meeting intervention.

\section{Previous Research}

Social science research shows that in order to be effective, information about environmental problems should be multifaceted, covering ecology, relevant procedures or actions, the effectiveness of these, and the social context (Hines et al., 1987; Kaiser and Fuhrer, 2003; Roczen et al., 2014). If information is framed in terms of the threat posed and the efficacy of actions people may undertake, information may also alter emotions toward the environment ( $\mathrm{Li}, 2014)$, which in turn may affect attitudes and behavior (Carmi et al., 2015). Glikman et al. (2012) who specifically focused upon LCs showed that residents with more knowledge about wolf and brown bear biology reported more positive feelings toward these animals, associated with normative beliefs of protecting them. Slagle et al. (2013) in an online communication experiment showed the importance of balancing the information on wolves to also communicate the benefits of the species to humans.

The source of the information is critical both with regard to its trustworthiness and the choice of information content communicated (Arbieu et al., 2019). Studies on media coverage of LCs state that media exaggerates risks and fuel people's feelings of fear (Penteriani et al., 2016), but such studies also show that the framing of information about LCs with joint efforts between media and conservationists can be changed (Hathaway et al., 2017). Whereas, large carnivore information centers have been pointed out as having a potential as a reliable and credible source of information (Arbieu et al., 2019). Trust is important in wildlife management (Zajac et al., 2012), and plays into people's feeling of fear (Johansson et al., 2012, 2016b). Moreover, situational factors matter, for example if the place of information allows experience of animals and their habitats or not, affects how people respond. Zoos have been shown to be more efficient than class rooms when it comes to students learning about wolves and possibility to affect attitudes (Orazem et al., 2019). Similarly, an experiential education approach in field resulted in a positive view of interactions with coyotes among local residents (Sponarski et al., 2016). So far, few studies specifically concern the role of information about LCs on people's feelings of fear of these animals. The role of factual knowledge of the feared species in reducing fear is according to Field et al. (2001) debatable, but practical knowledge of how to behave has been demonstrated to reduce fear and improve coping in encounters with the feared animal, at least among people with dog phobia (Hoffman and Odendaal, 2001; Hoffman and Human, 2003). 
Johansson et al. (2016c, 2017, 2019) based on theory of human-environment interaction (Küller, 1991) and appraisal theory of emotion (Scherer, 2001), proposed that informational interventions aimed to reduce fear of brown bears must alter the individual's appraisal of a potential encounter with these animals. Arguing that the information content should relate to the aspect of coping potential of the appraisal of a potential encounter with the feared animal. Coping potential is the ability of the individual to perceive that he or she can handle a situation, including the possibility of gaining control of the situation and feeling that one has the power to do so (e.g., Scherer, 2001). More specifically this is the individual's framing of a situation in terms of threat and efficacy in handling a situation. In the case of fear of a potential encounter with LCs the coping potential seems to involve the perceived vulnerability e.g., the perceived dangerousness the animal pose, the predictability of the animal behavior, and the controllability of one's own reaction in an encounter situation. Moreover, the social trust in managing authorities should be targeted in interventions aimed at providing people with mental tools to handle their fear of LCs (Johansson et al., 2012, 2016c). Using this theoretical framework, the effect of different informational interventions on LCs has previously been developed evaluated in a series of independent studies without possibilities to directly compare effects across interventions for fear of encountering brown bears. This research suggests that among people who are motivated to participate, information meetings arranged by managing authorities to address fear of brown bears and guided walks with exposure to brown bear/brown bear habitat may tap into the appraisal process behind the feeling of fear, e.g., increasing social trust, and decreasing perceived vulnerability. Moreover, the affective experiences associated with a potential brown bear encounter comprising valence varying along unpleasantness-pleasantness and arousal varying along deactivation-activation can be altered, in particular by increasing a positive valence. Also, self-reported fear of an encounter has been shown to decrease (Johansson et al., 2016c, 2017, 2019). An effect on self-reported avoidance behavior has been identified for the guided walks. Currently there is no long-term evaluation of the effect of information meeting about brown bears on self-reported fear and avoidance behavior. The effect over time to people's daily life seems however critical to assess the usefulness of information meetings as an intervention in wildlife management. The information content has also been integrated in a permanent brown bear exhibition, but this intervention has not previously been evaluated with regard to it's effect on fear.

In the guided walks, the participants themselves in addition to information content and the exposure component, in openended questions pointed to the importance of the close interaction and dialogue with the guide (Johansson et al., 2019). This brought the attention not only to the content but also how it is presented, the format of communication. The metacommunication is a constitutive aspect of all communication situations (Bateson, 1972). Meta-communication is multi modal and include verbal and non-verbal representations in the shape of speech, sounds, gestures, facial expressions, body motions, as well as choice of text, pictures and movies (Watzlawick et al., 1967; Craig, 2016). One aspect of meta-communication is performed through explicit verbal expressions with an explicit coordination function (Craig, 2016) for example; what did you say, what do you mean, what is the meaning of that word, when will we start, who are you, I am happy/sad/worried/competent etc. Such explicit meta-communication is involved both in symmetric communication situations (e.g., conversations in which several actors have approximately the same opportunities to contribute) and in communication situations with an asymmetric distribution of initiatives (e.g., when a lecturer speaks to an audience). Meta-communication is done through as well-symmetrical interaction, e.g., questions and answers, and through unidirectional statements, e.g., when a speaker makes self-corrections. The explicit meta-communication is involved in processes of constituting trust and legitimacy in procedures and information sources (van Nijnatten, 2006). It is also through the explicit meta-communication that disagreements and misconceptions are detected and managed (Schegloff, 1992).

\section{Study Aims}

This study aims to increase the understanding of the potential of information meetings as an intervention to address fear of brown bears among people who fear encountering these animals. The study analyses the explicit meta-communication between presenters and participants during the information meetings, investigates the effects of the meetings over time and compares the effects of the meetings with an individual visit to a permanent brown bear exhibition at a large carnivore information center, and the effects of exposure in the form of guided walks close to brown bears or in brown bear habitat, respectively. The outcomes of the study thereby provide a solid basis to understand how information meetings can be an appropriate intervention to introduce to address fear of encountering brown bears.

The empirical work in a mixed-method approach combines a descriptive qualitative analysis of explicit meta-communication during information meetings with experimental designs to test the effects of information meetings on fear and fear-related variables and comparing these effects with the effects of a visit to a permanent brown bear exhibition and the effects of guided walks with exposure to brown bears or their habitat.

\section{METHODS}

\section{Participants}

The main sample included 70 people (28-78 years, $m=57$ years, $73 \%$ females, $27 \%$ males) who participated in information meetings about brown bears held at the large carnivore information center De5Stora, Järvsö, Sweden during the spring 2017. The main sample was compared with two reference samples. The first reference sample included visitors to the permanent brown bear exhibition at the De5Stora $(N=62,19-$ 77 years, mean age $=44$ years, $71 \%$ females, $29 \%$ males, data collected autumn 2018). The second reference sample included people who had participated in the evaluation of guided walks with exposure to brown bears/brown bear habitats conducted in collaboration with a large carnivore park in Orsa, Sweden $(N=$ $55,20-84$ years, $m=52$ years, $73 \%$ females, $27 \%$ males). The 
latter data was collected in 2016 and has previously been reported in detail by Johansson et al. (2019).

\section{Ethic}

Participants in all three sub-samples were recruited via advertisement in local public media, via home pages and Facebook, and on-site before entering the large carnivore center. It was clearly stated in the advertisement that the study was directed toward people who were concerned about encountering brown bears in the wild. It should be noted that all participants thereby were motivated themselves to obtain further understanding of the interaction between humans and brown bear. Upon arrival the study's aim, general procedure, and that one was allowed to withdraw at any time without any consequences, were explained. All participants signed an informed consent and had the opportunity to debrief with staff after the intervention if they wished so. The research procedure for the guided walks with exposure to brown bears has previously been submitted to the Regional Ethical Review Board at Lund University, which declared that the research needed no further ethical review (DNR 2013/220).

\section{Information Meetings}

In total four information meetings were held with between 18 and 33 participants by two different presenters, both affiliated with the Swedish Wildlife Damage Center that has a national responsibility to provide information and education about management of protected wildlife, such as large carnivores (https://www.slu.se/centrumbildningar-och-projekt/ viltskadecenter/). The presenters have many years of experience from fieldwork and research on large carnivores, and extensive experience of communicating at public information meetings. The information meetings lasted $\sim 2 \mathrm{~h}$ including a short coffee break.

The information content presented at the meetings was based on scientific research conducted on bears in Scandinavia by the Scandinavian Brown Bear Research Project (SBBRP) (see also Johansson et al., 2017, 2019). The content was chosen to relate to coping potential in the appraisal process, e.g., framing brown bears in terms of perceived threat and efficacy in handling an encounter. The content was designed to tap into identified antecedents of fear, i.e., appraisal of vulnerability and social trust. The first part of the information served to clarify the sender of the information, the presenter gave a short introduction of him/herself and the role of the organization (WDC) to establish a common basis. Thereafter the presentation focused on present bear populations, including range and population size, with specific reference to the latest official monitoring reports and tailored to the area of the meeting. This was to establish a common frame for the meeting. The second part of the information covered basic biology, including research methods and study areas. The presentation also explained radio-collaring of bears, home range sizes, prey species, social organization and reproduction. The third part of the presentation was specifically designed for this study, and focused on the interaction with humans. Based on behavioral studies of bears in Scandinavia, typical bear behavior close to humans was described (relating to predictability of animal behavior). Frequency of attacks on humans in Sweden, and globally, was reported. Human behavior known to increase risk of an attack when encountering large carnivores during outdoor activities (e.g., hiking with and without dogs, hunting) were also presented (relating to perceived danger of a potential encounter). Finally, specific recommendations were given on how to behave in areas with large carnivores and when encountering carnivores, in order to reduce risk of attacks (tapping into perceived controllability of one's own behavior).

Presenters were instructed to present data and personal experiences of encounters with bears, without commenting on political decisions or adding personal values. They were instructed to listen to participants' personal experiences and feelings in conversations. During presentations, questions posed for clarification were answered, but other issues raised were discussed at the end of the meetings, to ensure that the structure of the meetings was as similar as possible.

\section{The Exhibition}

The large carnivore center De5Stora is an information center commissioned by the Swedish Environmental Protection Agency to disseminate knowledge-based and impartial information about the large carnivores in Sweden with the objective to support dialogue with the public and between stakeholders representing different interests. Visitors to the exhibition walked around the exhibition independently at their own pace. The exhibition at the information center covered the same scientific content as the information meetings as it is largely built around the research results from the SBBRP including the present bear populations, including range and population size and brown bear biology. The exhibition also describes typical bear behavior close to humans and specific recommendations are given on how to behave in areas with large carnivores and when encountering carnivores, in order to reduce risk of attacks. The exhibition is designed to stimulate all senses and includes photos, sound, smell, animal montage and interactive stations. The exhibition strives to give a multi-faceted picture about LCs in Sweden.

\section{Guided Walks With Exposure}

The guided walks were held in small groups of up to four participants and led by four different guides with several years of experience of fieldwork, research on bears linked to the SBBRP, and extensive experience of communicating with the public. The guided walks included the same information content as the information meetings, but, the guides related the information to the visible signs in the physical environment with either fenced brown bears in a large carnivore park where animals are kept in their natural habitat or following GPS tracks of a wild living brown bear in the forests outside the large carnivore park (for detailed information about the guided walks see Johansson et al., 2019). Participants in the guided walks spent $1-2 \mathrm{~h}$ with the guide either in the large carnivore park or in the forests around the park. The guides received the same instructions as the presenters 
at the information meetings, with regard to presenting information without commenting on political decisions or adding personal values. They were also instructed to listen to participants' personal experiences and feelings in conversations, but the walks allowed for more dialogue and the information content could thereby be better adapted to the individual participant's need.

\section{Questionnaire}

All participants completed a first set of self-report questionnaires comprising self-reported feeling of fear, valence and arousal, avoidance, vulnerability, social trust and factual knowledge and socio-demographics immediately before the interventions (Time 1, T1). Post-tests comprising the similar self-reports and written questions about their experience of the intervention were completed immediately after all three interventions (Time 2, T2). Participants in the information meeting intervention were also mailed a questionnaire and asked to complete the self-reports once more (Time 3, T3) 6 months later (after the major mushroom and berry-picking season). The selfreports were collected using previously published questionnaire items for assessing fear-related variables The formulation of questionnaire items and response scales are reported in Table 1.

\section{Observation of Explicit Meta-Communication}

During the information meetings an observer coded the presenters' verbal interaction with the participants using a classification instrument with certain attention to explicit metacommunication sequences. The classification was based on what was addressed in communicative sequences. Usually "sequence" refers to several turns where different speakers respond to each other. However, in a lecture or public speech situation a sequence can consist of more than one turn followed by each other from the same speaker. The overarching classification of communication content consisted of three classes:

(1) Sequences which address the current conversation and its preconditions and consequences (meta-communication) (subcategories are explained below).

(2) Sequences which address fear of bear or encounters with bears.

(3) Sequences which address other issues than (1) and (2).

Quotes from sequences of category 1 and 2 were notified and coded into originally nine subcategories which during the coding were extended to 11 categories. The coding was analyzed further in terms of frequencies of different codes/types of explicit meta-communication and the different variations within each coding category was analyzed and described (summarized under Results). Sequences sometimes address more than one type of explicit meta-communication, and subsequently the same sequence can be coded into more than one category. Note that it is the communication problems that are addressed in metacommunication that has been coded, not the communication problem per se (e.g., distrust, misconceptions).

\section{RESULTS}

\section{Participants Experience of Information Meeting Content and Format of Communication}

When the participants themselves were asked about their experiences of the information meetings at $\mathrm{T} 2$ they reported that the information content had been rather easy to understand $(M$ $=4.73, S D=0.53$, scale ranging from 1 very difficult to 5 very easy), that the information was considered credible $(M=4.76$, $S D=0.49,1=$ not at all credible, $5=$ most credible) and that all participants' questions were responded to in an equal manner by the presenters $(M=4.80, S D=0.49,1=$ not at all equal, $5=$ very much equal). The presence of misunderstandings between the presenters and the participants were very few $(M=1.36$, $S D=0.741=$ not at all present, $5=$ very much present), and the participants did not feel that the presenter avoided certain topics $(M=1.11, S D=0.40,1=\operatorname{did}$ not avoid not at all, $5=$ avoided always).

\section{Explicit Meta-Communication Observed}

In total 249 occurrences of explicit meta-communication were observed and coded during the four information meetings. The distribution of initiatives at all meetings suggests an asymmetrical communication, with a significant dominance of the presenters. The type of explicit meta-communication was also similar across the meetings.

The most frequently appearing code was "the speaker address her/himself," corresponding to $34 \%$ of the sequences. These sequences appear in three different shapes: in self-presentations, as a marker of intention, and as a marker of validity claim in a knowledge representation. Self-presentations are performed by the speakers by referring to experiences they have made, or with reference to positions or competences. Self-presentations are performed during the entire duration of the presentation and can be initiated both by the speaker her/himself or by a question from a participant. Codes which address the other in abstract terms without space or expectation of responses, i.e., "non-dialogic addressing of participants" appears in $20 \%$ of the sequences. This is when the presenter in his/her speech name and address the participants of the meeting, their intentions or experiences without expressing expectations of an answer. These communicative turns can for example be constructed as

Presenter: If by any chance you want to come close to a bear I was thinking we should watch a film clip. I believe that also if you are not bear experts you will still recognize what the bear wants when you watch this don't you?

When the presenters use abstract addressing of participants, they display inclusiveness to the participants; they demonstrate that they have the participants in mind, while simultaneously the asymmetric distribution of initiative in the communication is also confirmed. In some applications the participants are ascribed identity; the communicative turn expresses an expectation on what the participants are, what they know, do and wish. Future conversational sequences $(17 \%)$ are utterances which ask about or connect to what is anticipated will take place later in the 
TABLE 1 | Overview of the concepts measured by means of the questionnaire including formulation of items, response scale and for calculated indices the internal reliability.

\begin{tabular}{ll} 
Concept & Items \\
\hline Feeling of fear & \\
Index of eight items where four items were described for a solitary bear (as presented \\
below) and four identical items described for a female bear with cubs: \\
You are walking alone in the forest in an area in which you know there are bears. You \\
see a solitary bear that weighs over $80 \mathrm{~kg}$ and is $150 \mathrm{~cm}$ long, $50 \mathrm{~m}$ away. How strong \\
is your worry/fear that the bear will attack you? \\
You are in a group of three people walking together in the forest in an area in which you \\
know there are bears. You see a solitary bear that weighs over $80 \mathrm{~kg}$ and is $150 \mathrm{~cm}$ \\
long, $50 \mathrm{~m}$ away. How strong is your worry/fear that the bear will attack one of you? \\
You are walking in the forest with your dog in an area in which you know there are \\
bears. You see a solitary bear that weighs over $80 \mathrm{~kg}$ and is $150 \mathrm{~cm}$ long, $50 \mathrm{~m}$ away. \\
How strong is your worry/fear that the bear will attack the dog and you? You are \\
walking in the forest with your child or grandchild (under 12 years old) in an area in \\
which you know there are bears. You see a solitary bear that weighs over $80 \mathrm{~kg}$ and is \\
150 cm long, $50 \mathrm{~m}$ away. How strong is your worry/fear that the bear will attack the \\
child and you?
\end{tabular}

Valence and Arousal ${ }^{\mathrm{b}}$

Avoidance

Vulnerabilityc

Social trust ${ }^{\mathrm{d}}$

Factual knowledge
Index of five items:

Have you during the last 2 months avoided any of the following activities in the forest because there might be brown bears in the forest?

walking alone

picking berries or mushrooms

exercising,

walking the dog,

bringing small children into the forest

Index of six items:

I believe that if I came close to a brown bear I would be harmed

I do not believe brown bears could be dangerous to me

I believe that I would be able to deal effectively with a brown bear by myself if

encountered

If a brown bear came nearby I would probably not feel in control

I think that the movement of brown bears is impossible to understand in advance

I find brown bears to be predictable in their movements

Four items:

I trust that the County Administration Board, manages problematic situations involving brown bears with consideration to people who live in bear areas

I trust that the Swedish Wildlife Damage Center, manages problematic situations

involving brown bears with consideration to people who live in bear areas

I trust that the Swedish Environmental Protection Agency manages problematic

situations involving brown bears with consideration to people who live in bear areas

I trust that the Government manages the brown bear population with consideration to people who live in bear areas

Nine multiple-choice items:

Mark which of the four pictures that show brown bear footprints

Mark which of the four pictures that show brown bear scats

Mark which of the four pictures that show marks made by brown bears

What is the weight of an adult male brown bear in spring?

In what situation is the risk highest for a brown bear attack on a human?

What signal is a brown bear giving by rising up on its hind legs when encountering a

human?

What does it mean that a brown bear puffs and blows its nose when encountering a

human?

What should you do if a bear detects you on $30 \mathrm{~m}$ distance?

How should you behave while in the forest if you don't want to encounter brown bears?
Response scale

Internal reliability

Cronbach's $\alpha$ T1

Scale from 0 to 10

0.96

$0=$ None at all

$10=$ Very strong

Axis ranging from 1 to 5

Valence

0.85

1 = Unpleasant

5 = Pleasant

Arousal:

$1=$ Not aroused

$5=$ Aroused

Frequency of avoidance

average based on number

of applicable items:

$1=$ Never

2 = Sometimes

$3=$ Often

$4=$ Always

$5=\mathrm{n} / \mathrm{a}$

Likert scale

$1=$ Completely disagree

$5=$ Completely agree

Likert scale

0.89

1 = Completely disagree

5 = Completely agree

$\mathrm{n} / \mathrm{a}$

Total knowledge score based on number of correct answers 1-9 $\mathrm{n} / \mathrm{a}$

(Continued) 
TABLE 1 | Continued

\begin{tabular}{|c|c|c|c|}
\hline Concept & Items & Response scale & $\begin{array}{c}\text { Internal reliability } \\
\text { Cronbach's } \alpha \mathrm{T} 1\end{array}$ \\
\hline Experience of the meeting & $\begin{array}{l}\text { Five items: } \\
\text { Did you find the information easy to understand? } \\
\text { Did you find the information credible? } \\
\text { Where all questions responded to in an equal manner? } \\
\text { Where there any misunderstandings between the presenter and the participants? } \\
\text { Did you feel that the presenter avoided certain topics? }\end{array}$ & $\begin{array}{l}1=\text { very difficult } \\
5=\text { very easy } \\
1=\text { not at all credible, } \\
5=\text { most credible } \\
1=\text { not at all equal, } \\
5=\text { very much equal } \\
1=\text { not at all present } \\
5=\text { very much present } \\
1=\text { avoided not at all } \\
5=\text { avoided very much }\end{array}$ & $\mathrm{n} / \mathrm{a}$ \\
\hline
\end{tabular}

a Self-reported fear of brown bear (Johansson et al., 2019).

${ }^{b}$ Affect grid (Russell et al., 1989; Johansson et al., 2012).

${ }^{c}$ The cognitive vulnerability model (Johansson et al., 2012). Items in italics are reversed in the coding.

dSalient-value similarity (Johansson et al., 2012).

conversation, and previous conversational sequences (16\%) refer to something already said. Both the presenters and participants perform such sequences. It is for example frequently occurring that a participant asks a question and the presenter responds "we will come to that." This also appears in another version where a participant asks "will you talk about xx." These sequences confirm the mutual expectation of asymmetric distribution of initiatives; the participants agree that it is the presenter who decides and have control of what is brought up and when. A special form of explicit meta-communication addresses a previous turn in which a participant asks a question and the lecturer values the quality or relevance of the question:

Presenter: Very interesting question. But if you make a lot of sounds...

Although most of the explicit meta-communication was expressed by the presenters, there was a lot of interaction between presenters and participants. One example is when the presenter addresses another actor in a concrete dialogical question expecting an answer (15\%). This appears when the presenter asks the participants about their experiences and when participants asks the presenter about her/his experiences. These questions serve as a control of relevance; the presenter demonstrate that the participants' experiences are relevant in the context of the meeting. Explicit meta-communication that address the speaker and other participants as "we" (6\%) also appears and is initiated both by the presenter and the participants, often in sequences of disposition talk, coordination or switch of topic. It functions as a confirmation of that the information meeting is something "we" perform and achieve together.

Presenter: I thought we should look at some tracks

The explicit meta-communication during the meetings is also used to identify, solve and prevent potential problems in communication which can be perceived as threats against inter-subjective understanding, such as misconceptions (11\%), concepts (5\%), trust/distrust (4\%), and disagreement (2\%). Explanations of concepts are often initiated by the same speaker who mentioned the potentially problematic concept without any visible indication of problems with meaning from the participants side. Sometimes explanations of concepts are initiated by another speaker.

Presenter: The home range of the females overlap, that is, they are...

Misconceptions are identified and repaired by as well the presenters and other participants, and is sometimes done through multi-turn interaction. Addressing misconceptions often appear for the external observer as unclear or incomplete, and are often performed through joint, collaborative communication efforts. Hesitating and questioning tone are often resulting in repair turns.

Presenter: There was a case in... Hälsingland [county in Sweden]

Participant: Jämtland [another county]

Distrust and disagreement appear in a few rare cases when participants or presenters express doubt about validity claims made by other:

Participant: Is that something known or is it a political statement?

Presenter: Well, I am researcher and not employed by county board [public authority], so not politically restricted...

In our last example a participant expresses her/his trust in the validity and relevance of the information displayed during the meeting:

Participant: This [refer to the information meeting] is how one get informed about reality.

\section{The Effect of Information Meetings Over Time}

The effect of information meetings over time was analyzed by ANOVA, repeated measures with Time (T1, T2, T3) as withinsubject factor. The analyses were carried out for each one of the investigated psychological concepts and show that the 
participation in the information meetings are likely to contribute to reduce fear. Mean values and standard deviations are reported in Table 2. Among the participants at the information meetings Fear significantly decreased over time $\left[F_{(2,68)}=46.77, p<\right.$ $\left.0.001, \eta_{p}^{2}=0.58\right]$. Post-hoc comparisons indicated that fear was significantly higher at $\mathrm{T} 1$ as compared to T2 and T3, but that fear was significantly lower at T2 than at T3. Valence (the positive affective experience) significantly increased $\left[F_{(2,68)}=37.31, p<\right.$ $\left.0.001, \eta_{p}^{2}=0.52\right]$. Post-hoc comparisons indicated that valence was significantly lower at $\mathrm{T} 1$ than at $\mathrm{T} 2$ and $\mathrm{T} 3$, but that valence was significantly higher at T2 than at T3. Arousal (the level of activation) did not significantly differ between T1, T2 and T3 $\left[F_{(2,68)}=1.29\right.$, n.s. $]$. Neither did Avoidance change significantly change between $\mathrm{T} 1$ and $\mathrm{T} 3$ (not measured at $\mathrm{T} 2$ ) $\left[F_{(1,69)}=\right.$ 1.86, n.s.].

Vulnerability (e.g., the composite measure covering perceived danger, predictability of animal behavior and uncontrollability of personal reaction) significantly decreased over time $\left[F_{(2,68)}=\right.$ 83.23, $\left.p<0.001, \eta_{p}^{2}=0.71\right]$. Post-hoc comparisons indicated that vulnerability was significantly higher at T1 than at T2 and T3, but that vulnerability was significantly lower at T2 than at T3. Trust significantly increased $\left[F_{(2,68)}=8.24, p=0.001, \eta_{p}^{2}=0.20\right]$. Posthoc comparisons indicated that trust was significantly lower at $\mathrm{T} 1$ than at T2 and T3. Trust did not significantly differ between $\mathrm{T} 2$ and T3. Knowledge significantly increased from T1 to T2 (not measured at T3) $\left[F_{(1,69)}=35.36, p<0.001, \eta_{p}^{2}=0.34\right]$.

\section{Comparison of Information Meetings, Exhibition, and Guided Walks}

The effect of information meetings in comparison with the other two interventions was analyzed in a $3 \times 2$ analysis of variance repeated measures with Intervention type (information meeting, exhibition, guided walk) as between subject factor and Time (T1, T2) as within subject factor. The results show that all interventions may contribute to reduce fear but the strongest effects could be seen for participation in a guided walk followed by information meeting and exhibition. Mean values and standard deviations are reported in Table 2 and effect sizes are summarized in Figure 1. The mean values for Fear decreased from $\mathrm{T} 1$ to $\mathrm{T} 2$ with all three intervention types and a main effect of Time, $F_{(1,184)}=304.25, p<0.001, \eta_{p}^{2}=0.62$, was shown. A significant interaction effect between Intervention type and Time indicate that the decrease differs between intervention types, $F_{(2,184)}=17.51, p<0.001, \eta_{p}^{2}=0.16$. The interaction effect suggests that participation in the guided walks was more likely to be efficient in reducing fear than participation in an information meeting or an exhibition. This interpretation is supported by the calculation of Cohen's $d_{\mathrm{av}}$ and the corresponding 95\% confidence interval per intervention type. Figure 1A shows the relations between the obtained effect sizes.

The mean values for Valence increased with all three intervention types and a main effect of Time, $F_{(1,184)}=193.88$, $p<0.001, \eta_{p}^{2}=0.51$, was shown. Moreover, an interaction effect between Intervention type and Time, $F_{(2,184)}=9.66, p<0.001$, $\eta_{p}^{2}=0.10$, indicated that the effect differed in size between the different interventions. Figure 1B shows the relations between the obtained effect sizes, suggesting that participation in a guided walk is more efficient to strengthen a positive valence than an information meeting, which in turn might be somewhat more likely to be efficient in strengthening a positive valence than a visit to an exhibition. The mean values for Arousal decreased from T1 to T2 for all intervention types, and a main effect of time $F_{(1,184)}$ $=4.44, p=0.037, \eta_{p}^{2}=0.02$, was shown. However, the effect size was weak and no significant interaction was shown, $F<1$, suggesting that the three interventions were equal in this respect.

The mean values for Vulnerability decreased with all three intervention types and a main effect of Time, $F_{(1,184)}=491.88$, $p<0.001, \eta_{p}^{2}=0.73$, was shown. However, there was also an interaction effect between time type of intervention for the dependent variable Vulnerability, $F_{(2,184)}=18.00, p<0.001$, $\eta_{p}^{2}=0.16$, due to the differences in decrease between measures at $\mathrm{T} 1$ and $\mathrm{T} 2$ for the different interventions. Figure 1D shows the relations between the obtained effect sizes, suggesting that participation in an information meeting is more likely to be efficient in reducing perceived vulnerability than is an individual visit to the exhibition, but less likely to efficiently reduce vulnerability than participation in a guided walk.

The mean values for Trust increased for from T1 to T2 for all intervention types, and a main effect of time, $F_{(1,184)}=20.13$, $p<0.001, \eta_{p}^{2}=0.10$, was shown. No significant interaction effect between Intervention type and Time was shown, $F_{(2,184)}$ $=1.49$, n.s. This means that the interventions are likely to be about equally efficient in strengthening trust. The mean values for Knowledge increased for from T1 to T2 for all intervention types, and a main effect of time, $F_{(1,184)}=64.21, p<0.001, \eta_{p}^{2}=0.26$, was shown. No significant interaction effect could be shown, $F<$ 1. Consequently, the interventions were about equally efficient in increasing knowledge.

\section{DISCUSSION}

The communication interventions examined here seem to have a clear potential to change the appraisal outcomes of a potential brown bear encounter among people who are motivated to participate. The information meeting may well be introduced when the information content and format are carefully considered to address people's feelings of fear, and the effects are likely to last at least over a 6-months period. The information meetings were particularly efficient in reducing self-reported feelings of fear, perceived vulnerability in a potential brown bear encounter, and to increase valence, e.g., a positive affective experience in response to brown bears. In addition, social trust and knowledge increased. The comparison of the three communication interventions investigated shows however that also other interventions could be feasible. The strongest effects were obtained by the guided walks with exposure, followed by the information meetings, and the exhibition. The present results thereby corroborate and synthetize previous separate findings from studies on information meetings and guided walks, and relates these findings to the use of permanent exhibitions. Guided walks with exposure carried out with small groups of 
TABLE 2 | Mean values and standard deviations at T1, T2, and T3 for the three interventions.

\begin{tabular}{|c|c|c|c|c|c|c|}
\hline \multirow[b]{2}{*}{ Variable } & \multicolumn{2}{|c|}{$\begin{array}{l}\text { Information meeting } \\
\qquad N=70\end{array}$} & \multicolumn{2}{|c|}{$\begin{array}{l}\text { Exhibition } \\
\qquad N=62\end{array}$} & \multicolumn{2}{|c|}{$\begin{array}{l}\text { Exposure } \\
N=55\end{array}$} \\
\hline & $M$ & $S D$ & $M$ & $S D$ & $M$ & $S D$ \\
\hline Fear T1 & 7.19 & 2.39 & 7.54 & 1.95 & 8.19 & 1.85 \\
\hline Fear T2 & 4.93 & 2.72 & 5.92 & 2.46 & 4.48 & 2.42 \\
\hline Fear T3 & 5.62 & 2.56 & - & - & - & - \\
\hline Valence T1 & 1.92 & 1.05 & 2.10 & 0.88 & 1.74 & 0.93 \\
\hline Valence T2 & 2.72 & 1.13 & 2.71 & 1.10 & 3.05 & 1.04 \\
\hline Valence T3 & 2.39 & 1.21 & - & - & - & - \\
\hline Arousal T1 & 4.22 & 0.72 & 4.42 & 0.68 & 4.43 & 0.69 \\
\hline Arousal T2 & 4.15 & 0.67 & 4.38 & 0.70 & 4.29 & 0.74 \\
\hline Arousal T3 & 4.07 & 0.90 & - & - & - & - \\
\hline Avoidance T1 & 2.36 & 0.83 & - & - & - & - \\
\hline Avoidance T3 & 2.22 & 0.90 & - & - & - & - \\
\hline Vulnerability T1 & 3.52 & 0.76 & 3.56 & 0.82 & 3.67 & 0.74 \\
\hline Vulnerability T2 & 2.41 & 0.70 & 2.81 & 0.82 & 2.16 & 0.45 \\
\hline Vulnerability T3 & 2.73 & 0.81 & - & - & - & - \\
\hline Social trust $\mathrm{T} 1$ & 3.28 & 0.97 & 3.28 & 1.11 & 3.34 & 0.90 \\
\hline Social trust T2 & 3.59 & 0.80 & 3.40 & 0.97 & 3.68 & 0.96 \\
\hline Social trust T3 & 3.58 & 1.06 & - & - & - & - \\
\hline Knowledge T1 & 6.68 & 1.59 & 6.06 & 1.62 & 6.49 & 1.52 \\
\hline Knowledge T2 & 7.70 & 1.12 & 6.93 & 1.48 & 7.17 & 1.27 \\
\hline
\end{tabular}

participants come with higher costs, than information meetings with 20-30 participants at a time or individual visits to permanent exhibitions. At an overarching level the result thereby confirms that a trade-off between effort and effect has to be considered.

Observations of the explicit meta-communication performed during the information meetings indicated that the presenter and other participants shared similar expectations of content and format of the meeting. Presenters and participants mutually expected and accepted an asymmetric distribution of initiatives, in which the presenter was in charge of content and format and where the participants' questions and experiences were treated as relevant. A typical characteristic of such mutual expectations of asymmetry in initiative is the presenters frequent non-dialogic addressing of the participants ("I believe you are interested in...") and the addressing of what issues will be brought up later in the lecture ("we will come to that"/"will you talk about"). However, the non-dialogic addressing of the participants comes with a risk. If the presenter and the audience have different expectations about the symmetry of the initiatives, and if the presenter is unaware of this matter, the non-dialogic addressing may expose the presenter's misconception of the participants' expectations. If the addressing of participants is done in a dialogical way, i.e., through making space for answers of questions and confirmation or rejection expectations, misunderstandings can be detected earlier and managed before they evolve into a problem. A frequent use of dialogic addressing in this conventional form of information meetings is however also associated with the risks of not being able to touch upon all dimensions of the topic within the given time frame, which may leave some participants unsatisfied.

The observed explicit meta-communication is in line with cultural expectations of an information meeting in Sweden, and the presenters and participants collaborated in their communication to maintain the asymmetric distribution of initiatives. However, even if these sequences occurred less frequent, there were also several occasions observed where the participants were asked direct questions, and sequences in which the distribution of initiatives were more symmetric, and questions about understanding and trustworthiness were asked and answered. The observed explicit meta-communication was congruent with the participants' self-reported experiences of the meetings. The participants found the information content credible and easy to understand, they reported that all topics and questions raised were treated in an equal way and there were very few misunderstandings between presenters and participants. The presenters seem to have managed to establish credibility and create a positive social atmosphere during the meetings where misconceptions and misunderstandings could be addressed and solved. Taken together the observations indicate that a sufficient balance was created between asymmetric and symmetric distribution of initiative between the presenters and the participants. However, further research and practice of information meetings should pay attention to what expectations participants may have regarding content and format. It would also be desirable to further consider the balance between symmetric and asymmetric meta-communication especially 

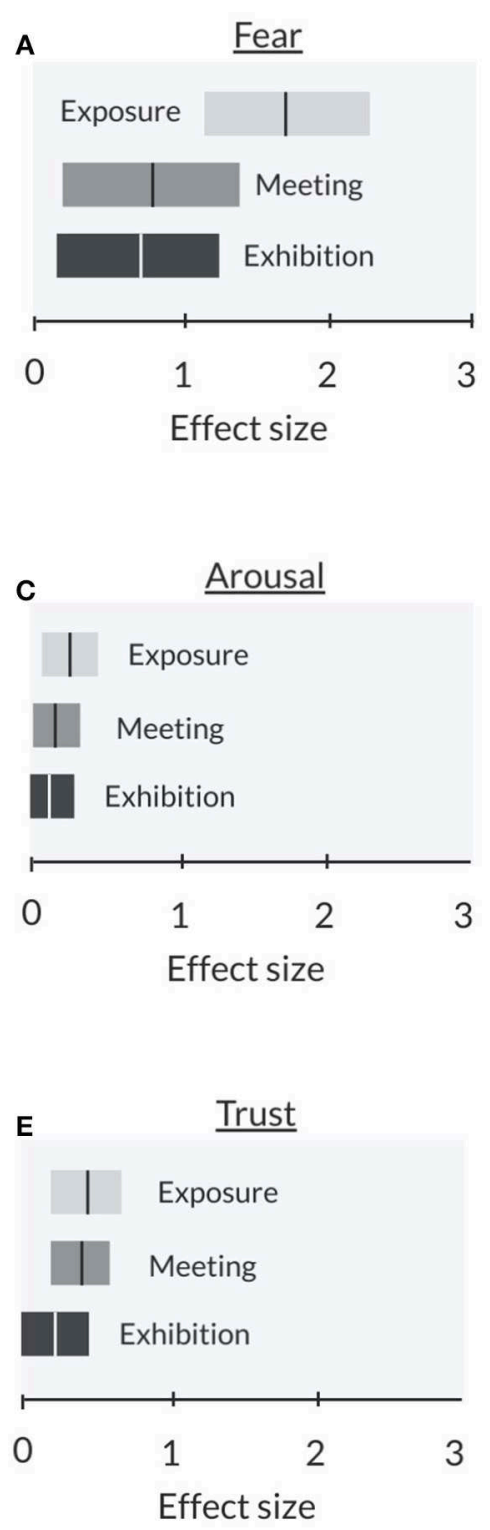
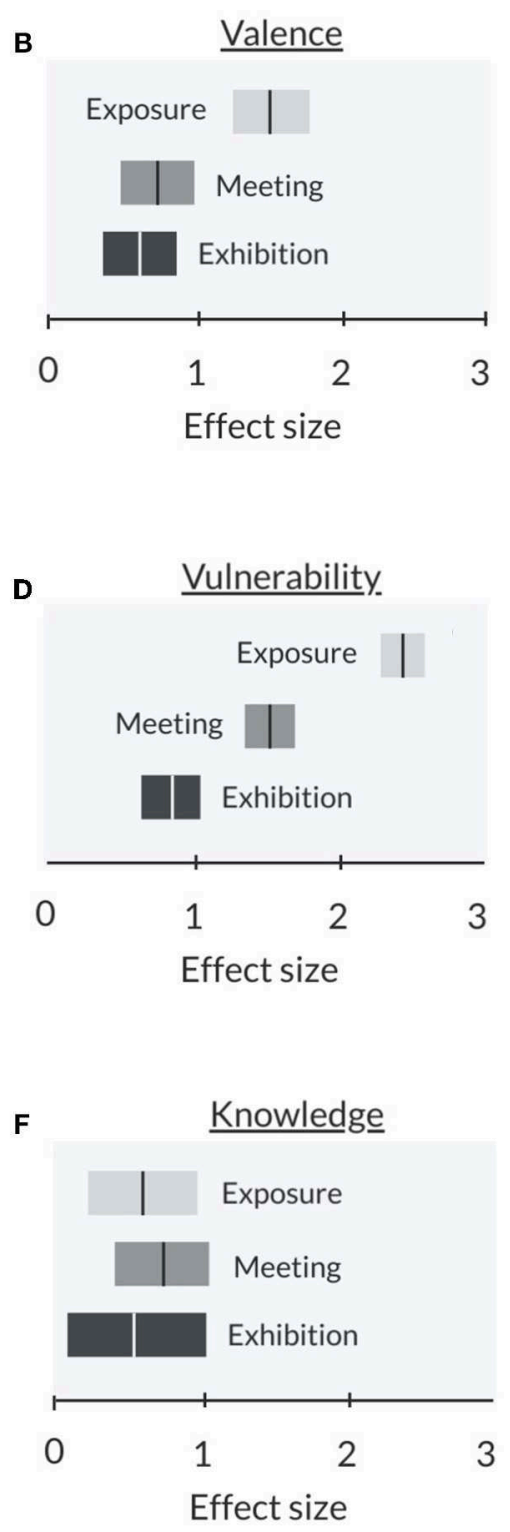

FIGURE 1 | The figure show the relations between the obtained effect sizes (marked with a line in the boxes) and their confidence intervals (shown by the length of the boxes) for the three interventions Guided walks with exposure, Information meeting, and Exhibition for the six dependent variables; Fear (A), Valence (B), Arousal (C), Vulnerability (D), Trust (E), and Knowledge (F).

if information meetings are introduced to address fear in conflictual situations.

The questionnaire results indicate that the participants' possibilities to adequately cope with a potential brown bear encounter has been strengthened by participation in the information meetings. The effect was strongest immediately after the meetings (T2) but the effects to some extent lasted over 6 months (T3). Especially the appraisal of vulnerability in a potential brown bear encounter decreased, meaning that the participants thought about an encounter as less dangerous, that they would better predict the animal behavior and control their own reaction in an encounter situation. Although selfreported fear decreased and valence increased, no significant change could be seen in self-reported avoidance behavior. This means either that the participants continued to avoid situations where they possibly could encounter a brown bear or that a decrease in avoidance possible seen a few weeks after the meeting had regressed over 6 months, this conclusion is supported by the partial regression seen in fear, valence and vulnerability. The lack of effect in avoidance behavior suggests that other approaches to address fear, such as exposure interventions, are required if there are expectations of behavioral change to occur. No measure of avoidance was made at T2 as no behavioral change could be expected immediately after the meeting. The effect on trust in managing authorities was relatively weak as indicated by the effect sizes (Figure 1). One challenge to 
the formation of trust may be built in the set-up of the information meetings involving the physical staging of the premises-scene and rows of chairs as well as expectations on one-way communication both among presenters and audience. In situations where trust building would be the primary aim alternative interventions build around two-way communication are more feasible (Lewicki, 2006; Lucero and Wallerstein, 2013; Bergman et al., 2016).

The study further considered the efficiency of introducing public information meetings compared to individual visits to permanent exhibitions on brown bears and guided walks with exposure to brown bears/brown bear habitat. These two additional interventions relied on the same information content, but in the exhibition intervention participants had to interpret the information on their own-without professional support, and in the exposure intervention the participants had access to a real brown bear setting and in the small group the information can be more personally tailored to the participants needs. In line with previous research the results show that all three intervention types would be relevant for managing authorities to introduce in situations when the public report feelings of fear. However, considering that the information content was the same across the interventions but the effect sizes differed, this comparison may suggest that the more realistic setting that can be used and the more informal interaction that can be established the more likely the information content may play into the appraisal process and consequently fear responses. In this study we analyzed the explicit meta-communication only in the information meetings, but it would still be relevant to compare the difference in meta-communication ability between the three interventions. In a guided-walk with few participants and an informal interaction format guide and participants have almost unlimited access to interaction with each other and the threshold to initiate meta-communication is quite low for all participants. The participants that visited the exhibition did not talk to staff which means that they had no possibility to ask questions and there was therefore a lack of explicit metacommunication. A manned, or partially manned, exhibition may strengthen the effect and further studies should explore the potential role of staff at exhibitions in facilitating communication around the information content. Further studies should make stronger efforts to compare the effects of the interventions over time.

More women than men showed interest in participating in all three interventions. One reason may be that in brown bear areas fear of bears among women to a higher degree than among men can be explained by perceived vulnerability (Johansson et al., 2012). Another reason may be that hunters, who are primarily males, are offered courses by hunting organizations. These courses partly focus upon brown bear behavior (Støen et al., 2018).

\section{Implication for Practice}

This study show that authorities involved in wildlife management have several communication options in situations where they are faced with feelings of fear among the public. Each one of the interventions investigated has advantages and disadvantages, which makes it difficult to say that one intervention is better than the other. Most importantly people the interventions are feasible to introduce when those concerned themselves are motivated to participate. A critical task from a management perspective is then to decide in which situations each one of the interventions evaluated (information meetings, guided walks with exposure, and exhibitions) would be more suitable. Even though the guided walks come out as the most effective intervention tested here, in reducing fear, it seems practically and economically impossible to bring over 100,000 Swedes on guided walks in groups of three to five participants. Rather we propose that the choice of intervention should be based on the individual's need. The magnitude of fear varied somewhat between respondents in our studies. In this perspective it would be most beneficial to introduce guided walks to those expressing a high level of fear that clearly impact on their everyday life or activities. Information meetings can be introduced when the level of fear is intermediate, using an information content that taps into the appraisal of a brown bear encounter and a format that allows for an explicit meta-communication that meets expectations on information meetings where the presenter dominates the initiative, and where misconceptions and misunderstandings could be addressed and solved. The effect of the information meeting was however more moderate compared to the guided bear walks, but the cost is also reduced to only a fraction as a typical information meeting can be attended by 20 to 30 people. The results also suggest that an exhibition with the same content as the other two interventions can contribute to reduce selfreported feelings of fear. However, the effect is lower than for the other interventions. The advantage of an exhibition, especially if it is accessible located, is that a lot of people can be reached at a relative low cost and the intervention would be more or less immediately available when there is a need. It is proposed that managing authorities could use the results of the present study to set-up a communication strategy to more efficiently reach the management goals with regard to reduced public fear of encountering brown bears.

It should be recognized that the appraisal process differs between species and socio-demographic groups (Johansson et al., 2012, 2016b). As an example, the appraisal of vulnerability is relatively more strongly associated with fear of brown bears while a lack of social trust seems more important to fear of wolves. If the investigated interventions should be applied to fear of wolves the information content needs to be changed to better match the antecedents of fear of wolves. Moreover, the explicit meta-communication may be even more important as social trust would be a critical aspect. The results from this study can be expected to be valid for other wildlife species that may look and live different compared to brown bears, but where the appraisal process is similar. As a first step toward developing communication interventions to address people's fear of other species as for example wild boar (Sus scrofa) or Moose (Alces alces), should thus be to understand what appraisal aspects are most critical to the self-reported fear of the species. 


\section{DATA AVAILABILITY STATEMENT}

The datasets generated for this study are available on request to the corresponding author.

\section{AUTHOR CONTRIBUTIONS}

$\mathrm{MJ}, \mathrm{LH}$, and AF analyzed the data. MJ drafted the manuscript. LH, AF, LT, O-GS, and JF read and commented upon the text. All authors contributed to the planning and performance of the study.

\section{REFERENCES}

Anon (2016). Nationell förvaltningsplan för björn 2014-2019 [National Management Plan for Bears in Sweden 2014-2019]. Stockholm: Naturvårdsverket Förlag.

Arbieu, U., Mehring, M., Bunnefeld, N., Kaczensky, P., Reinhardt, I., Ansorge, H., et al. (2019). Attitudes towards returning wolves (Canis lupus) in Germany: exposure, information sources and trust matter. Biol. Conserv. 234, 202-210. doi: 10.1016/j.biocon.2019.03.027

Baruch-Mordo, S., Breck, S. W., Eilson, K. R., and Broderick, J. (2011). The carrot or the Stick? Evaluation of education and enforcement as management tools for human-wildlife conflicts. PLOS ONE 6:e15681. doi: 10.1371/journal.pone.0015681

Bateson, G. (1972). Steps to an Ecology of Mind. London: Jason Aronson Inc.

Bergman, C., Dellve, L., and Skagert, K. (2016). Exploring communication processes in workplace meetings: a mixed methods study in a Swedish healthcare organization. Work 54, 533-541. doi: 10.3233/WOR-162366

Bombieri, G., Nanni, V., del Mar Delgado, M., Fedriani, J. M., López-Bao, J. V., Pedrini, P., et al. (2018). Content analysis of media reports on predator attacks on humans: toward an understanding of human risk perception and predator acceptance. Bioscience 68, 577-584. doi: 10.1093/biosci/biy072

Carmi, N., Arnon, S., and Orion, N. (2015). Transforming environmental knowledge into behaviour: the mediating role of environmental emotions. $J$. Environ. Educ. 46, 183-201. doi: 10.1080/00958964.2015.1028517

Chapron, G., Kaczensky, P., Linnell, J. D. C., von Arx, M., Huber, D., Andrén, H., et al. (2014). Recovery of large carnivores in Europe's modern humandominated landscapes. Science 346, 1517-1519. doi: 10.1126/science.1257553

Clayton, S., Litchfield, C., and Geller, S. E. (2013). Psychological science, conservation, and environmental sustainability. Front. Ecol. Environ. 11:351. doi: $10.1890 / 120351$

Craig, R. T. (2016). "Metacommunication," in The International Encyclopedia of Communication Theory and Philosophy, eds K. Bruhn Jensen, R. T. Craig, J. D. Pooley, and E. W. Rothenbuhler (Hoboken, NJ: JohnWiley \& Sons Inc.), 1227-1231.

Decker, D. J., Riley, S. J., and Siemer, W. F. E. (2012). Human Dimensions of Wildlife Management. 2nd Edn. Baltimore, MD: Johns Hopkins University Press.

Dunn, W. C., Elwell, J. H., and Tunberg, G. (2008). Safety education in bear country: are people getting the message? Ursus 19, 43-52. doi: 10.2192/15376176(2008)19[43:SEIBCA]2.0.CO;2

Field, A. P., Argyris, N. G., and Knowles, K. A. (2001). Who's afraid of the big bad wolf: a prospective paradigm to test Rachman's indirect pathways in children. Behav. Res. Ther. 39, 1259-1276. doi: 10.1016/S0005-7967(00) 00080-2

Glikman, J. A., Vaske, J. J., Bath, A. J., Ciucci, P., and Boitani, L. (2012). Residents' support for wolf and bear conservation: the moderating influence of knowledge. Eur. J. Wildl. Res. 58, 295-302. doi: 10.1007/s10344-011-0579-x

Gore, M. L., Knuth, B. A., Scherer, C. W., and Curtis, P. D. (2008). Evaluating a conservation investment designed to reduce human-wildlife conflict. Conserv. Lett. 1, 136-145. doi: 10.1111/j.1755-263X.2008.00017.x

Hathaway, S. R., Bryant, M. A. E., Draheim, M. M., Vinod, P., Limaye, S., and Athreya, V. (2017). From fear to understanding: changes in media

\section{FUNDING}

This research was funded by grant DNR 2016/1169 and DNR 2018/1193 from the Swedish Environmental Protection Agency.

\section{ACKNOWLEDGMENTS}

The authors would like to thank all the staff at the De 5 Stora for facilitating the data collection. Emily Montgomerie for observing meta-communication during the information meetings, and all participants for taking part in the interventions.

representations of leopard incidences after media awareness workshops in Mumbai, India. J. Urban Ecol. 3, 1-7. doi: 10.1093/jue/jux009

Hines, J. M., Hungerford, H. R., and Tomera, A. N. (1987). Analysis and synthesis of research on responsible environmental behavior: a meta-analysis. J. Environ. Educ. 18, 1-8. doi: 10.1080/00958964.1987.9943482

Hoffman, W. A., and Human, L. H. (2003). Experiences, characteristics and treatment of women suffering from dog phobia. Anthrozoös 16, 28-42. doi: $10.2752 / 089279303786992323$

Hoffman, W. A., and Odendaal, J. S. J. (2001). The effect of behavioral therapy on dog phobia response patterns. Anthrozoös 14, 29-37. doi: $10.2752 / 089279301786999571$

Jacobs, M. H. (2012). Human emotions toward wildlife. Hum. Dimens. Wildl. 17, 1-3. doi: 10.1080/10871209.2012.653674

Johansson, M., Ferreira, I., Støen, O-G., Frank, J., and Flykt, A. (2016a). Targeting human fear of large carnivores-many ideas but few known effects. Biol. Conserv. 201, 261-269. doi: 10.1016/j.biocon.2016.07.010

Johansson, M., Flykt, A., Frank, J., and Støen, O.-G. (2019). Controlled exposure reduces fear of brown bears. Hum. Dimens. Wildl. 24, 363-379. doi: 10.1080/10871209.2019.1616238

Johansson, M., Frank, J., Støen, O.-G., and Flykt, A. (2017). An evaluation of information meetings as a tool for addressing fear of large carnivores. Soc. Nat. Resour. 30, 281-298. doi: 10.1080/08941920.2016.1239290

Johansson, M., and Karlsson, J. (2011). Cognitive interpretation and subjectively experienced fear of brown bear and wolf. Hum. Dimens. Wildl. 16, 15-29. doi: 10.1080/10871209.2011.535240

Johansson, M., Karlsson, J., Pedersen, E., and Flykt, A. (2012). Factors governing human fear of brown bear and wolf. Hum. Dimens. Wildl. 17, 58-74. doi: 10.1080/10871209.2012.619001

Johansson, M., Sandström, C., Pedersen, E., and Ericsson, G. (2016b). Factors governing human fear of wolves: moderating effects of geographical location and standpoint on protected nature. Eur. J. Wildl. Res. 62, 749-760. doi: 10.1007/s10344-016-1054-5

Johansson, M., Støen, O.-G., and Flykt, A. (2016c). Exposure as intervention to address human fear of bears. Hum. Dimens. Wildl. 21, 311-327. doi: 10.1080/10871209.2016.1152419

Kaiser, F. G., and Fuhrer, U. (2003). Ecological behavior's dependency on different forms of knowledge. Appl. Psychol. 52, 598-613. doi: 10.1111/1464-0597.00153

Küller, R. (1991). "Environmental assessment from a neuropsychological perspective," in Environment, Cognition and Action, eds T. Gärling, and G. W. Evans (New York, NY: Oxford Univ. Press), 111-147.

Lewicki, R. J. (2006). “Trust, trust development and trust repair," in The Handbook of Conflict Resolution Theory and Practice, eds M. Deutsch, P. T. Coleman and E.C. Marcus (San Francisco, CA: Jossey-Bass), 92-119.

Li, S. S.-C. (2014). Fear appeals and college students' attitudes and behavioral intentions toward global warming. J. Environ. Educ. 45, 243-257. doi: 10.1080/00958964.2014.930399

Lucero, J. E., and Wallerstein, N. B. (2013). "Trust in community-academic research partnerships. Increasing the consciousness of conflict and trust development," in The Sage Handbook of Conflict Communication. Integrating Theory, Research and Practice, eds J. G. Oetzel and S. Ting-Toomey (London: Sage), 537-562. doi: 10.4135/9781452281988.n23 
Manfredo, M. J. (2008). Who Cares About Wildlife? Social Science Concepts for Exploring Human Wildlife Relationships and Conservation Issues. New York, NY: Springer.

Orazem, V., Tomazic, I., Kos, I., Nagode, D., and Randler, C. (2019). Wolves' conservation through educational workshops: which method works best? Sustainability 11:1124. doi: 10.3390/su11041124

Penteriani, V., Delgado, M. M., Pinchera, F., Naves, J., FernándezGil, A., Kojola, I., et al. (2016). Human behaviour can trigger large carnivore attacks in developed countries. Sci. Rep. 6:20552. doi: 10.1038/ srep20552

Redpath, S. M., Young, J., Evely, A., Adamas, W. M., Sutherland, W. J., Whitehouse, A., et al. (2013). Understanding and managing conservation conflicts. Trends Ecol. Evol. 28, 100-109. doi: 10.1016/j.tree.2012. 08.021

Ripple, W. J., Estes, J. A., Beschta, R. L., Wilmers, C. C., Ritchie, E. G., and Wirsing, A. J. (2014). Status and ecological effects of the world's largest carnivores. Science 343, 151-162. doi: 10.1126/science.1241484

Roczen, N., Kaiser, F. G., Bogner, F. X., and Wilson, M. (2014). A competence model for environmental education. Environ. Behav. 46, 972-992. doi: 10.1177/0013916513492416

Russell, J. A., Weiss, A., and Mendelsohn, G. A. (1989). Affect grid: a single-item scale of pleasure and arousal. J. Pers. Soc. Psychol. 57, 493-502.

Schegloff, E. A. (1992). Repair after next turn: the last structurally provided defense of intersubjectivity in conversation. Am. J. Sociol. 97, 1295-1345. doi: $10.1086 / 229903$

Scherer, K. R. (2001). "Appraisal considered as a multi-level sequential checking," in Appraisal Processes in Emotion: Theory, Methods, Research, eds K. R. Scherer, A. Schorr, and T. Johnstone (New York, NY: Oxford University Press), 92-120.

Sjölander-Lindqvist, A. (2009). Social-natural landscape reorganised: Swedish forest-edge farmers and wolf recovery. Conserv. Soc. 7, 130-140. doi: 10.4103/0972-4923.58644
Slagle, K., Zajac, R., Bruskotter, J., Wilson, R., and Prange, S. (2013). Building tolerance for bears: a communications experiment. J. Wildl. Manage. 77, 863-869. doi: 10.1002/jwmg.515

Sponarski, C. C., Vaske, J. J., Bath, A. J., and Loeffler, T. A. (2016). Changing attitudes and emotions toward coyotes with experiential education. J. Environ. Educ. 47, 296-306. doi: 10.1080/00958964.2016.1158142

Støen, O.-G., Ordiz, A., Sahlén, V., Arnemo, J. M., Sæbø, S., Mattsing, G., et al. (2018). Brown bear (Ursus arctos) attacks resulting in human casualties in Scandinavia 1977-2016; management implications and recommendations. PLoS ONE 13:e0196876. doi: 10.1371/journal.pone.0196876

van Nijnatten, C. (2006). Meta-communication in institutional talks. Qual. Soc. Work 5, 333-349. doi: 10.1177/1473325006067364

Watson, R. (2009). Constitutive practices and garfinkel's notion of trust: revisited. J. Classical Sociol. 9, 475-499. doi: 10.1177/1468795X09344453

Watzlawick, P., Beavin, J. H., and Jackson, D. D. (1967). Pragmatics of Human Communication: A Study of Interactional Patterns, Pathologies, and Paradoxes. New York, NY: Norton.

Zajac, R. M., Bruskotter, J. T., Wilson, R. S., and Prange, S. (2012). Learning to live with black bears: a psychological model of acceptance. J. Wildl. Manage. 76, 1331-1340. doi: 10.1002/jwmg.398

Conflict of Interest: The authors declare that the research was conducted in the absence of any commercial or financial relationships that could be construed as a potential conflict of interest.

Copyright (c) 2019 Johansson, Hallgren, Flykt, Støen, Thelin and Frank. This is an open-access article distributed under the terms of the Creative Commons Attribution License (CC BY). The use, distribution or reproduction in other forums is permitted, provided the original author(s) and the copyright owner(s) are credited and that the original publication in this journal is cited, in accordance with accepted academic practice. No use, distribution or reproduction is permitted which does not comply with these terms. 